\title{
Nurses' Organizational Citizenship Behavior and Its Association to their Job Satisfaction
}

\author{
${ }^{1}$ Master Student, Faculty of \\ Nursing, King Abdulaziz \\ University, Jeddah, Saudi Arabia \\ ${ }^{2}$ Associate Professor, Public Health \\ Department, Faculty of Nursing, \\ King Abdulaziz University, \\ Jeddah, Saudi Arabia \\ ${ }^{3}$ Assistant Professor, Public Health \\ Department, Faculty of Nursing, \\ King Abdulaziz University, \\ Jeddah, Saudi Arabia
}

Ashwaq T AL-Ahmadi ${ }^{* 1^{*}}$ | Sabah M Mahran ${ }^{2}$ | Aziza A Rajab

\section{1 | INTRODUCTION}

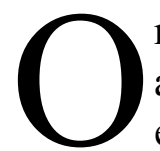
rganizational citizenship behavior (OCB) is a crucial concept which defined as a type of extra-role behaviors that are not involved in the reward and punitive policies of the organization which contributes to help and share information, reinforce endurance, a feeling of conscience, and com-

\begin{abstract}
Objective: To identify the level of organizational citizenship behavior and its relation to job satisfaction in the nursing field.

Methodology: One step search strategy includes an extended search in various databases: Cumulative Index Nursing and Allied Health Literature (CINAHL), MEDLINE, ProQuest, and google scholar. Twenty published studied between January 2015 and April 2020 were included in the review.

Results: Two themes emerged from the present review, which are nurses' organizational citizenship behavior level and the relationship between job satisfaction and nurses' organizational citizenship behavior. In the theme of nurses' organizational citizenship behavior level; seven studies found most nurses had a high level of OCB, three studies found they had higher than average, five studies demonstrated that they had a moderate level while only one study found their OCB on a low level. Regarding the other theme, three studies did not find a correlation between job satisfaction and $\mathrm{OCB}$, whereas three studies displayed that job satisfaction had a positive effect on OCB.

Conclusion: Most of the studies found that nurses had a high-level regard OCB. However, the result of studies regards the influence of job satisfaction on OCB were ambivalent.

Keywords: organizational citizenship behavior, organizational behavior, job satisfaction, work satisfaction, nurses
\end{abstract}

mendation the organization $[1,2]$. It is also defined as prosocial actions that maintain the well-being of individuals, groups, or organizations[3]. Organ (1988) identified five types to this voluntary behavior which are; conscientiousness (exceeding the minimum job requirements), sportsmanship (endurance behaviors), civic virtue (participating actively and compliance with the organizational issues), courtesy 


\section{INNOVATIVE JOURNAL}

(preventing work-related problems), and altruism (helping others)[4]. Williams \& Anderson (1991) classify these types in different approach. Altruism and courtesy as a category of organizational citizenship behavior- individual (OCB-I) which is defined as the behavior directed towards and benefits other individuals. While sportsmanship, conscientiousness and civic virtue as a category of organizational citizenship behavior- organization (OCB-O) which is defined as behaviors directed towards and benefits the organizations[5].

Employees who have OCB engaged positively to the organization and display good relations with their colleagues [6]. The organizations can reach their goals when they go beyond their formal tasks and authorities and assist their co-workers [7].In the healthcare field, patient satisfaction , nursing performance, and the quality of patient care can be increased when the nurses exhibited more OCBs[8, 9].

Job satisfaction is considering as one of the essential issues that influencing organizational citizenship behavior [10]. Nurses engaged in citizenship behaviors and perform high level of effort when they satisfied with their organizations that promote their welfare and value their participations [11].Numerous studies from various fields reported that satisfied employees will be willing to exhibit their citizenship behavior [12-15]. Meanwhile, there is no published review debate on the level of OCB and the influence of job satisfaction on these discretionary behaviors in the nursing field. Therefore, it was necessary to conduct the current review.

Supplementary information The online version of this article (https://doi.org/10.15520/ijmhs.v10i10.3 116) contains supplementary material, which is available to authorized users.

Corresponding Author: Ashwaq T AL-Ahmadi*

Master Student, Faculty of Nursing, King Abdulaziz

University, Jeddah, Saudi Arabia

Email:ashwaqtalala88@hotmail.com.

\section{2 | MATERIALS AND METHODS}

Search Strategy:One step search strategy has been utilized to determine the published studies relevant to the topic reported in English language texts. It includes an extended search in various databases: Cumulative Index Nursing and Allied Health Literature (CINAHL), MEDLINE, ProQuest, and google scholar.

Key Search Terms:The search terms used were based on the review objectives divided into two parts to facilitate and maintain a more accurate search process.

Determine Nurses' Organizational Citizenship Behavior Level: Organizational citizenship behavior, organizational citizenship behavior level, nurses, nurse, and nursing.

Find out The relationship between Job Satisfaction and Nurses' OCB: Job satisfaction, work satisfaction, career satisfaction, organizational citizenship behavior, nurses or nurse or nursing.

The search was initiated with every keyword and was further developed by grouping and joining terms together using Boolean operators to select the best literature review. To widen or narrow the joined keywords, the researcher used Boolean operators (AND and OR) in all databases. The literature inclusion criteria included the studies that addressed organizational citizenship behavior level and the relationship between OCB and job satisfaction. Full- text papers were published between January 2015 and April 2020. The exclusion criteria for this review involved the studies explain OCB and its correlation with job satisfaction in a non- nursing field.

Study selection process: A large number of studies resulted from searching in databases. Duplicate studies removed after studies were filtered, the remaining studies titles and abstracts were checked and excluded according to the inclusion criteria. Using the strategy mentioned before, the researcher initially retrieved 395 articles reviewed and selected for inclusion. Thirty-four articles were excluded due to duplicate. The remaining studies were 361, which screened for the title. The researcher eliminated 321 articles after the title and abstract screening; 20 articles were excluded after the full-text screening. 
After that, 20 studies were retained (two studies from MEDLINE, six studies from CINAHL, one study from ProQuest, and 11 studies from google scholar). This selection process is indicated below in Figure : PRISMA flow diagram.

Each study critically appraised and using matrix review that includes the title, aim, sample, country, year, author, design, and results of the selected papers as a method for facilitating the writing and summarizing the most related studies and identifying the main themes of the literature review.
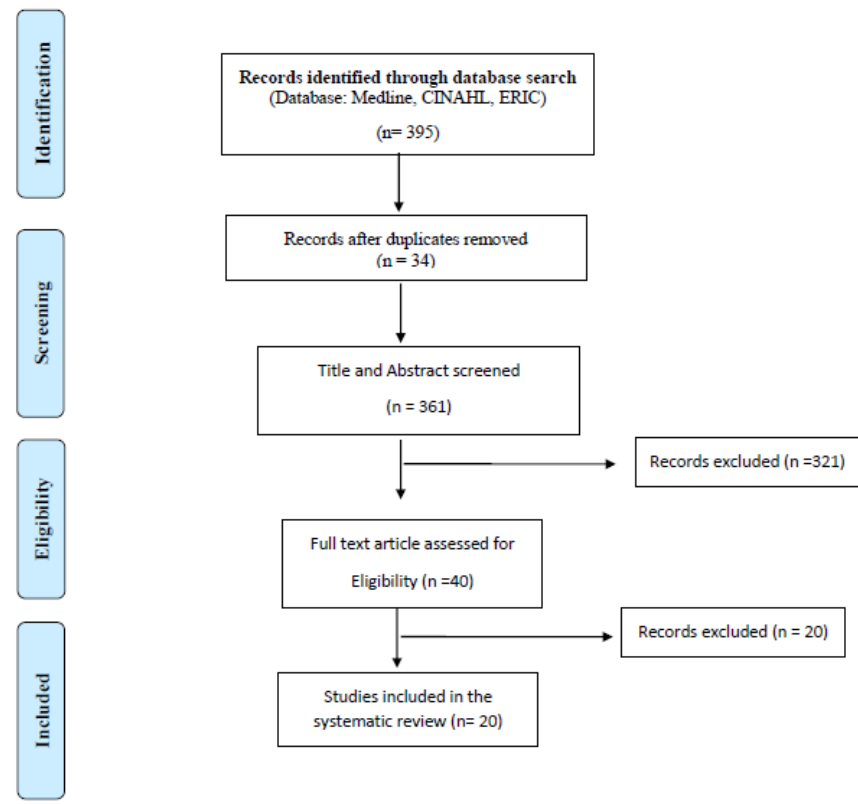

FIGURE 1: PRISMA Flow Diagram

\section{3 | RESULT}

Nurses' organizational citizenship behavior level:The level OCB of the employee is critical for developing organizations, while only limited studies have focused on the nursing field [16]. An Iranian study aimed to identify the correlation between emotional intelligence and OCB among 150 nurses working in critical and emergency units. The findings regard OCB level found on a high level, and the altruism dimension had the maximum mean score [17].Similar results found in two studies, one study conducted in Iran among 301 nurses, had at least one year of work experience[18]; while the other study was done in Indonesia among 175 nurses[19].
Furthermore, a correlational study in Iran surveyed 250 nurses in 12 teaching hospitals to examine OCB and its relation to an ethical climate and ethical leadership. The study result indicated that the mean score for OCB among nurses was 80.75, which means they had a high level[20].

Moreover, an Egyptian descriptive study aimed to explore the correlation between OCB and psychological capital for 109 staff nurses. The study was found the OCB level of staff nurses on a high level according to their perceived. The highest level was for altruism, whereas civic virtue had the lowest level[21].

Additionally, two studies in Egypt revealed that more than half of nurses had a high OCB level. One of them was conducted among 310 staff nurses who had work experience at least three years, while the other surveyed 29 nurse managers and 150 staff nurses[22, 23].

Nevertheless, only $10 \%$ of the 250 nurses had a high OCB level, whereas near to half had a low level in a descriptive correlational study in Egypt[24].

On the other side, a study in South Korea used the cross-sectional design to determine the level of OCB for 219 nurses from two teaching hospitals. The OCB score was higher than the average rate[25]. Similar results found in a correlational study conducted in Iran among 201 nurses [26].

Likewise, a descriptive study was conducted in Iran examined 373 nurses working in 15 governmental hospitals. The results found that the five subscales of OCB achieved higher than average rate, and the conscientiousness subscale had the highest level[27].

However, in Taiwan, a cross-sectional descriptive study sought to investigate organizational citizenship behavior level among 167 male nurses who were divided according to the years of experiences. The findings indicated that their perception for OCB was moderate, the highest mean score was for civic virtue, followed by sportsmanship and helping behavior. The male nurses who had 2-5 years' work experience reported the lowest OCB level[16].

Moreover, a study in Iran collected the data from 214 nurses working in the largest teaching hospital. According to the findings, the nurses expressed a 
medium level, the behaviors of altruism and conscientiousness were found on a high level while the civic virtue, courtesy,

and sportsmanship behaviors had a low level. This study interpreted the results as indicating that nurses may not be interested in engaging in the organization's issues and have low attentiveness to procedures that avoid harm to their institution[28].

Furthermore, an Egyptian correlational study analyzed data from 384 nurses and found the highest proportion of them had average levels of OCB. The altruism dimension had the highest mean, while civic virtue was the lowest[29]. In line with previous studies, one correlational study conducted in Iran, which surveyed 130 nurses staff and indicated that nurses had a moderate level[30].

One study conducted in Egypt among 261 staff nurses with experience of at least one year showed that $46 \%$ of respondents had a moderate level of OCB, whereas only $23 \%$ had a high level[31].

The previous studies demonstrated many strategies to enhance OCB among nurses. Tofighi and her colleagues declared that the managers in healthcare facilities need to establish organized and functional policies and procedures that deal with emotional intelligence [17]. Nursing manager should coach their staff to be aware of their personal emotions and for those of others as well as manage them professionally[32]. Furthermore, other studies displayed that the nurse's leaders have to be focus on improving organizational identification, maintain organizational justice, considered opportunities to participate in decision-making and periodic evaluation of citizenship behavior required[16, 24, 26]. Finally , two studies suggested the nursing education program to be concentrate on leadership style workshops and provide periodic counseling and courses regard OCB to staff nurses[18, 20].

The relationship between job satisfaction and nurses' organizational citizenship behavior: A few studies discussed the relationship between those two variables in nursing profession. A cross-sectional descriptive correlational predictive study in the United States analyzed the correlation between job satisfaction and OCB among 206 nurse staff, the nurse managers, and the nurse administrators. The result indicated that no relation between job satisfaction and OCB [33]. A similar result was found in a correlational study that surveyed 373 nurses in 15 public hospitals in Iran[27].

In line with the previous studies, a descriptive study was conducted in Iran which revealed that job satisfaction not had direct influence on OCB as well as it does not mediate the a association between OCB and organizational justice [26].

In contrast, another study from Iran was carried out to identify the correlation between job satisfaction and OCB for 270 staff nurses of social security hospitals. The results revealed that job satisfaction positively affects OCB [34].

A study was conducted in Indonesia and analyzed data from 292 nurses from three private hospitals to assess the direct influence of job satisfaction against OCB and the indirect influence of spiritual leadership on OCB across job satisfaction. The findings of the study

clarified that job satisfaction had significant direct influences on OCB and a significant indirect influence on the correlation between OCB and spiritual leadership [35].

Finally, a study was implemented among 100 Indonesian nurses. This study reported that job satisfaction effect positively on the OCB level for nurses. Add to that, this study was found the perceptions of nurses toward the reward system influenced their OCB level by job satisfaction[36].

\section{4 | CONCLUSION}

The review results concluded that most of the studies found that nurses had a high-level regard OCB. All studies used self-report questionnaires, which could affect the accuracy of the results. So, the evaluation of nurses' OCB by their managers and conducted observational studies could be required. However, the result of studies regards the relationship between job satisfaction and OCB were ambivalent. This result may be due to a dearth in nursing researches that highlighted the influence of job satisfaction on organizational citizenship behavior. Therefore, further investigations are needed in this field.

Conflicts of interest: The author displayed no con- 
flicts of interest.

Funding: No funding availed to conduct this review.

\section{REFERENCES}

1. Bolino MC, Grant AM. Academy of Management Annals; 2016.

2. Khaleh L, Naji S. The relationship between organizational commitment components and organizational citizenship behavior in nursing staff. International Journal of Medical Research \& Health Sciences. 2016;5(5):173-179.

3. Agheli R; 2017.

4. Qian X, Zhang M, Jiang Q. Leader Humility, and Subordinates' Organizational Citizenship Behavior and Withdrawal Behavior: Exploring the Mediating Mechanisms of Subordinates' Psychological Capital. International journal of environmental research and public health. 2020;(7):17-17.

5. Young S, J. Mediating Effect of Social Capital between Transformational Leadership Behavior and Organizational Citizenship Behavior in Hospital Nurses. Journal of Korean Academy of Nursing Administration. 2017;23(5):558-566.

6. Hemakumara M, Khatibi A, Johar M. Job satisfaction and organizational citizenship behavior among the administrative staff of state universities in Sri Lanka. International Journal of Management Sciences and Business Research. 2018;7(8):40-44.

7. Mahmoud A, Ibrahim S. Factors in nurses' organizational citizenship behavior. IOSR Journal of Nursing and Health Science. 2016;5(2):22-28.

8. Ruhana I. The Effect of Quality of Work Life (QWL) on Job Satisfaction and Organization Citizenship Behavior (OCB) (A Study of Nurse at Numerous Hospitals In Malang, Indonesia). Journal of Public Administration Studies. 2019;4(2):51-58. Available from: https:// dx.doi.org/10.21776/ub.jpas.2019.004.02.2. doi :10.21776/ub.jpas.2019.004.02.2.

9. Miao RT. Perceived organizational support, job satisfaction, task performance and organizational citizenship behavior in China. Journal of Behavioral and Applied Management. 2011;12(2):105-105.

10. El-Aliem SMF, Hamouda GM; 2020.

11. Kazemipour F, Amin SM. The impact of workplace spirituality dimensions on organisational citizenship behaviour among nurses with the mediating effect of affective organisational commitment. Journal of Nursing Management. 2012;20(8):n/a-n/a. Available from: https://dx. doi.org/10.1111/jonm.12025. doi:10.1111/jonm .12025 .

12. Mohamed HAE, L. The Relationship between Quality of Work Life and Organizational Citizenship Behavior among Nurses at El-Mansoura Health Insurance Hospital. Zagazig Nursing Journal. 2018;14(1):148-159.

13. Williams LJ, Anderson SE. Job Satisfaction and Organizational Commitment as Predictors of Organizational Citizenship and In-Role Behaviors. Journal of Management. 1991;17(3):601617. Available from: https://dx.doi.org/10.1177/ 014920639101700305. doi:10.1177/014920639 101700305.

14. Elsayed EM, Gafel HS. On the Periodic Solutions of Some Systems of Difference Equations. Communications in Advanced Mathematical Sciences; 2018. Available from: https://dx. doi.org/10.33434/cams.442662. doi:10.33434/c ams.442662.

15. Yu HY. Organizational citizenship behaviour of men in nursing professions: Career stage perspectives. Collegian. 2018;25(1):19-26.

16. Altuntaş S, Baykal Ü; 2014. 
INNOVATIVE JOURNAL

17. Prasetio AP, Yuniarsih T, Ahman E. Job Satisfaction, Organizational Commitment, and Organizational Citizenship Behaviour in Stateowned Banking. Universal Journal of Management. 2017;5(1):32-38. Available from: https: //dx.doi.org/10.13189/ujm.2017.050104. doi:10 $.13189 /$ ujm.2017.050104.

18. Tofighi M; 2015.

19. Jafarpanah M, Rezaei B. Association between organizational citizenship behavior and patient safety culture from nurses' perspectives: a descriptive correlational study. BMC Nursing. 2020;19(1):1-8. Available from: https://dx.doi. org/10.1186/s12912-020-00416-y. doi:10.1186 /s12912-020-00416-y.

20. Taghinezhad F, Safavi M, Raiesifar A, Yahyavi SH. Antecedents of organizational citizenship behavior among Iranian nurses: a multicenter study. BMC Research Notes. 2015;8(1):547547. Available from: https://dx.doi.org/10.1186/ s13104-015-1505-1. doi:10.1186/s13104-015-1 505-1.

21. Zami MS. A Conceptual Framework Outlining Factors Affecting the Acceptance of Earth as a Sustainable Building Material in the United Kingdom. European Center of Sustainable Development; 2020. Available from: https://dx.doi. org/10.14207/ejsd.2020.v9n3p241. doi:10.1420 7/ejsd.2020.v9n3p241.

22. Tabatabei SAN, Takapoo F, leilaeyoun A. The Effective of Job Satisfaction on Organizational Citizenship Behavior. International Journal of Academic Research in Business and Social Sciences. 2015;5(1):155-155. Available from: https://dx.doi.org/10.6007/ijarbss/v5-i1/1416. d oi:10.6007/ijarbss/v5-i1/1416.

23. Yurcu G, Akinci Z. Influence of organizational citizenship behavior on hotel employees' job satisfaction and subjective well-being. Advances in Hospitality and Tourism Research (AHTR). 2017;5:57-83.
24. Saxena S, Tomar K, Tomar S; 2019.

25. Pio RJ, Tampi JRE. The influence of spiritual leadership on quality of work life, job satisfaction and organizational citizenship behavior. International Journal of Law and Management. 2018;60(2):757-767. Available from: https://dx. doi.org/10.1108/ijlma-03-2017-0028. doi:10.11 08/ijlma-03-2017-0028.

26. Mohamed MR, Mohamed HR, F. Saad Influence of Organizational Justice on Organizational Citizenship Behavior among Nurses. Egyptian Journal of Health Care. 2019;10(2):264-276.

27. Metwally FG, Ata AA, Ahmed AK. Organizational Justice, Organizational Citizenship Behavior and Turnover Intention among Nurses: The Mediating Effect of Transformational Leadership. American Journal of Nursing. 2018;6(6):576-585.

28. Aloustani S, Atashzadeh-Shoorideh F, ZagheriTafreshi M, Nasiri M, Barkhordari-Sharifabad M, Skerrett V. Association between ethical leadership, ethical climate and organizational citizenship behavior from nurses' perspective: a descriptive correlational study. BMC Nursing. 2020;19(1):1-8. Available from: https://dx.doi. org/10.1186/s12912-020-0408-1. doi:10.1186/s 12912-020-0408-1.

29. Mahmoudi S, Hassani M, Aghlmand S. The Relationship between Organizational Justice and Organizational Citizenship Behavior among Nurses (Examining the Mediating Role of Organizational Commitment, Organizational Trust, and Job Satisfaction. Journal of Patient Safety \& Quality Improvement. 2017;5(2):513-520.

30. Zahran W; 2015.

31. Sutharjana NWK. Organizational citizenship behavior effect on patient satisfaction and loyalty through service quality (study on maternity hospitals in Indonesia). Int J Sci Technol Res. 2013;(2):288-299. 
32. Donohue. Book Reviews. The Steinbeck Review. 2020;17(1):97-97. Available from: https://dx.doi.org/10.5325/steinbeckreview.17. 1.0097. doi:10.5325/steinbeckreview.17.1.0097

33. Kamel JHK. An evaluation of etiologic factors in 300 patients treated in undergraduate endodontic program. University of Mosul; 2020. Available from: https://dx.doi.org/10. 33899/rden.2020.165810. doi:10.33899/rden.20 20.165810 .

34. Organ DW. Lexington Books/DC Heath and Com; 1988.

35. Charolyna SMW, Sukiswo D. THE EFFECT OF NURSE PERCEPTION IN WORK INCEN-
TIVE AND SATISFACTION SYSTEMS ON ORGANIZATIONAL CITIZENSHIP BEHAVIOR: A CASE STUDY AT GOVERNMENTAL HOSPITAL. Russian Journal of Agricultural and Socio-Economic Sciences. 2019;86(2).

36. White D, Grayson S. The importance of emotional intelligence in nursing care. J Comp Nurs Res Care. 2019;4:152-152.

How to cite this article: AL-Ahmadi* A.T., Mahran S.M., Rajab A.A. Nurses' Organizational Citizenship Behavior and Its Association to their Job Satisfaction. Innovative Journal of Medical and Health Science. 2020;1320-1326. https://doi.org/ 10.15520/ijmhs.v10i10.3116 